\title{
Inclusive Education: Mobile Serious Games for People with Cognitive Disabilities
}

\section{(Educación Inclusiva: Juegos Serios Móviles para Personas con Discapacidades Cognitivas)}

\author{
Angel Jaramillo Alcázar ${ }^{1}$, Sergio Luján-Mora², Luis Salvador-Ullauri ${ }^{3}$
}

\begin{abstract}
:
Nowadays, the use of mobile devices is increasingly frequent. In many occasions they are used as a means of entertainment for people through video games. Serious games is a category of video games used as teaching methods in different environments. They use fun as a strategy for the learning process. However, the vast majority do not focus on vulnerable groups such as people with cognitive disabilities, because they do not consider accessibility parameters in their design. Some video games development companies have proposed general guidelines for the implementation of accessible video games, but they have not been formalized as good practices or standards. This article presents a compilation and analysis of different accessibility guidelines for the development of mobile serious games for people with cognitive disabilities. It also proposes a model to evaluate the access of serious games for people with cognitive disabilities and applies it in a case study. Finally, an evaluation tool is proposed for mobile serious games developers focused on people with cognitive disabilities.
\end{abstract}

Keywords: accessibility assessment; accessibility guidelines; cognitive disabilities; mobile devices; serious games.

\begin{abstract}
Resumen:
El uso de dispositivos móviles es cada vez más frecuente. En muchas ocasiones son utilizados como un medio de entretenimiento para las personas a través de los video juegos. Los juegos serios son una categoría de video juegos utilizados como métodos de enseñanza en diferentes entornos. Ellos utilizan la diversión como una estrategia para el proceso de aprendizaje. Sin embargo, la gran mayoría no se enfoca en grupos vulnerables como las personas con discapacidad cognitiva, es decir, no consideran parámetros de accesibilidad en su diseño. Algunas empresas de desarrollo de video juegos han propuesto pautas generales para la implementación de este tipo de aplicaciones más no se han formalizado como buenas prácticas o estándares. El presente artículo presenta una recopilación y análisis de diferentes pautas de accesibilidad para el desarrollo de juegos serios móviles para personas con discapacidades cognitivas. Así también, propone un modelo de evaluación de la accesibilidad de juegos serios para dichas personas y lo aplica en un caso de estudio. Se propone una herramienta de evaluación para aquellos desarrolladores de juegos serios móviles enfocados en personas con discapacidades cognitivas.
\end{abstract}

Palabras clave: accesibilidad; discapacidad cognitiva; juegos serios; evaluación; dispositivos móviles.

\footnotetext{
1 Universidad de Las Américas, Quito - Ecuador (angel.jaramillo@udla.edu.ec).

2 University of Alicante, Alicante - Spain (sergio.lujan@ua.es).

${ }^{3}$ Centro de Educación Continua - EPN, Quito - Ecuador (Isalvador@cec-epn.edu.ec).
} 


\section{Introduction}

Nowadays, video games offer a wide variety of entertainment through different platforms. In 2016, the video games industry generated around $\$ 91$ billion worldwide, of which $\$ 41$ billion were from mobile devices market (Superdata, 2016). Serious games is a category of video games designed with the purpose of supporting the educational process (Michael \& Chen, 2006) and enable learning through entertainment (Koster, 2013). The development of this kind of video games will reach $\$ 5.5$ million in 2020 , at a compound annual growth rate of $16.38 \%$ between 2015 and 2020 (Markets and Markets, n.d.).

In addition, the development of serious games has increased for mobile platforms giving positive results. This effect is due to the fact that mobile devices have advantages over static equipment and computers (GameLearn, 2015). Often, teachers require different mechanisms to run their classes. So, serious games allow them to apply new teaching methods (Sauve, Senecal, Kaufman, Renaud, \& Leclerc, 2011). This kind of video games are designed to understand the students' necessities in the acquisition of knowledge (Ghannem, 2014) and the achieving of learning outcomes (Guillén-Nieto \& AlesonCarbonell, 2012).

Cisco identifies that about 563 million mobile devices and connections to the Internet were added in 2015 and the $36 \%$ of them belong to mobile devices (CISCO, 2017). The Radicati Group (2014) indicates that the number of worldwide mobile users is expected to increase to over 6.2 billion at the end of 2018 . It means that roughly $84 \%$ of the world population will be using mobile technology. In education, mobile devices offer a variety of ways to learn, communicate and collaborate (Gikas \& Grant, 2013). The use of this kind of technology has become necessary in the daily lives of all people, including people with disabilities.

In (Accessible University, 2016), accessibility is defined as the ability of an object to be used in spite of the condition or disability of a person. In (Holger, Tufiño, \& Estévez, 2017), for example, a device for assistance of blind people in the "cuarenta" game is presented. This is an accessibility solution in a game for people with blindness. Accessibility in digital platforms has led to the generation of some standards. One of them, WCAG 2.0, defines some accessibility guidelines for web content. These guidelines allow the web pages accessibility evaluation. In (Acosta \& Luján-Mora, 2017) for example, a review of the accessibility of the websites of the Ecuadorian universities of excellence is carried out. However, accessibility in video games is beginning to be considered by software developers. Thus, there are several players with disabilities. It is the case of Robert Kingett, a 24-year-old gamer from Chicago (IGN, 2014), who has cerebral palsy. His favorite genres to play are role-playing and action adventure games. He could not play if there were no video games that were accessible to people with different disabilities.

On the other hand, the World Health Organization (2011) estimates that about 15\% of the world population lives with a disability. Only in the United States this percentage increases to $19 \%$, that is, nearly one in five people have a disability in that country (US Census Bureau Public Information Office, n.d.). Many of them, with cognitive/mental disabilities, have to live with social, educational and entertainment limitations. People with cognitive disabilities have difficulty with one or more types of mental tasks than the rest (WebAIM, 2013).

According to the International Classification of Functioning, Disability and Health (ICF), mental functions are divided as shown in Table 1 (World Health Organization, 2001). These mental functions give rise to some cognitive disorders, such as: autism, Down syndrome, traumatic brain injury, attention deficit disorder, memory loss dyslexia, dyscalculia and learning disabilities in general. Taking into account all these mental functions and the cognitive disabilities that arise from them, it is important to determine what accessibility parameters should be taken into account for the development of serious games. 
Table 1. ICF - Mental Functions

\begin{tabular}{|c|c|}
\hline Categories & Subcategories \\
\hline Global Mental Functions & $\begin{array}{l}\text { - Consciousness functions } \\
\text { - Orientation functions } \\
\text { - Intellectual functions } \\
\text { - Global psychosocial functions } \\
\text { - Temperament and personality functions } \\
\text { - Energy and drive functions } \\
\text { - Sleep functions } \\
\text { - Global mental functions, other specified and unspecified }\end{array}$ \\
\hline Specific Mental Functions & $\begin{array}{l}\text { - Attention functions } \\
\text { - Memory functions } \\
\text { - Psychomotor functions } \\
\text { - Emotional functions } \\
\text { - Perceptual functions } \\
\text { - Thought functions } \\
\text { - Higher-level cognitive functions } \\
\text { - Mental functions of language } \\
\text { - Calculation functions } \\
\text { - Mental function of sequencing complex movements } \\
\text { - Experience of self and time functions } \\
\text { - Specific mental functions, other specified and unspecified }\end{array}$ \\
\hline
\end{tabular}

The rest of this article is organized as follows. In Section 2, we present a compilation of accessibility guidelines for the development of video games for people with cognitive disabilities. In Section 3, we propose a guidelines categorization for mobile serious games. Next, in Section 4, we evaluate a mobile serious game with the categorization proposed in Section 3. In Section 5, we discuss the results of our evaluation. Finally, in Section 6, we conclude the research and we outline our future works.

\section{Accessibility Parameters}

Each disability has its own accessibility parameters due to its particularities. There are video games that are accessible to people with cognitive disabilities. This is the case of Junk-Food Destroyer, a video game for helping adolescents with Down Syndrome to understand healthy eating (Hatzigiannakoglou, 2015). Also MEBook (Uzuegbunam, WingHang Wong, Cheung, \& Ruble, 2015) and MADRIGALE (Tore, Tore, Ludovico, \& Mangione, 2014) are video games to teach students with autism proper greeting behaviors and to promote phonological training in dyslexic child, respectively.

In previous works, we have studied some methods that assess the accessibility in mobile video games for people with visual (Jaramillo-Alcázar \& Luján-Mora, 2017), cognitive (Jaramillo-Alcázar, Luján-Mora, \& Salvador-Ullauri, 2017b), motor (Jaramillo-Alcázar, Luján-Mora, \& Salvador-Ullauri, 2017a) and hearing (Jaramillo-Alcázar \& Luján-Mora, 2018) impairments. For this study, we review several guidelines for video games development on mobile devices for people with cognitive disabilities. Until now, the scientific community has not given much interest to the accessibility of video games and has not proposed guidelines for the development of accessible video games. The most guidelines come from video game development groups. They focus their work on proposing accessibility features so that people with disabilities have the opportunity to enjoy and learn through video games. This contribution is of great importance because it offers the alternative of learning through serious games. 


\section{Guidelines Review}

Several parameters of accessibility and guides for video games are described by some authors. They are analyzed from the perspective of the disability or the type of device being used. In our research we will consider guidelines for cognitive disabilities.

The AbleGamers Foundation (2012) explains some important accessibility features that can be included into a video game. It defines three levels of accessibility, from a minimal scenario to an ideal one:

- Level one (Good): Minimum level, many things already being included as standard-practice.

- Level two (Better): Mix the need for greater accessibility and the easiness of implementation.

- Level three (Best): The result of covering all the accessibility barriers.

These levels cover from basic to advanced accessibility items that should be considered in development of video games. Taking into account cognitive disabilities, this study defines three, two and five accessibility guidelines for level one, two and three, respectively. Further, this study presents a section that describes six guidelines for mobile gaming accessibility:

- Touch: It is important to allow the largest area possible to be pressed in case of an involuntary shaking, tremors or low precision hitting.

- Multi-touch: If the game requires pressing multiple places at the same time, group them together to make press the buttons simultaneously.

- Alternative buttons: If the game requires a special feature such as tapping on the back of the device, rotating it, etc., allow for alternative means to be used to accomplish the same goal.

- High contrast: It is important for those with visual disabilities to see important areas of the game and navigation menus.

- Colorblind options: It is convenient that the mobile game have options for those with color deficiency or who are colorblind.

- Speed settings: It is adequate that the game has the ability to slow the game down to allow the gamer to play at a rate comfortable for their needs.

On the other hand, the International Game Developers Association (2004) with its Game Accessibility Special Interest Group, proposes a white paper. This describes the importance and the benefits of accessible games. Among them, the most prominent are: user satisfaction, reach the largest possible audience and the opportunity to learn new skills. This paper defines nine approaches for developers who want to provide cognitive accessibility to their games.

The Game Accessibility Guidelines authors (n.d.) propose a list of guidelines for the development of video games for people with disabilities. For the proposed guidelines, three categories are defined: basic, intermediate and advanced. These levels try to balance the number of people who benefit, the impact or difference made for those people and the cost to implement. In the case of cognitive impairment, this group defines seven, fifteen and five guidelines for the basic, intermediate and advanced categories, respectively. A step-bystep guide to work with these guidelines is also provided in this paper.

Finally, the MediaLT Company (2004) in its Game accessibility (UPS-project) defines a list of guidelines for the development of entertaining software for people with disabilities. This company determines five categories: level/progression, entries, graphics, sounds, installation and configuration, which have six, four, five, six and four guidelines, respectively.

Once all this information has been compiled, we present in Table 2 a summary of the authors and their respective guidelines. An analysis of these guidelines is made in the following section. Likewise, it will be determined those that are required in the mobile devices and their respective levels. 
Table 2. Guidelines per Author

\begin{tabular}{|l|l|r|}
\hline \multicolumn{1}{|c|}{ Author } & \multicolumn{1}{|c|}{ Categories } & Guidelines \\
\hline \multirow{4}{*}{ AbleGamers } & Level One & 3 \\
\cline { 2 - 3 } & Level Two & 2 \\
\cline { 2 - 3 } & Level Three & 5 \\
\cline { 2 - 3 } & Mobile Games & 6 \\
\hline IGDA & None & 9 \\
\hline \multirow{3}{*}{ Game Accessibility } & Basic & 7 \\
\cline { 2 - 3 } Guidelines & Intermediate & 15 \\
\cline { 2 - 3 } & Advanced & 5 \\
\hline \multirow{4}{*}{ MediaLT } & Level/Progression & 6 \\
\cline { 2 - 3 } & Entries & 4 \\
\cline { 2 - 3 } & Graphics & 5 \\
\cline { 2 - 3 } & Sounds & 6 \\
\cline { 2 - 3 } & Installation \& Configuration & 4 \\
\hline
\end{tabular}

There are video games that have incorporated these guidelines. Uncharted 4, an action-adventure video game, allows the configuration of several features, among them: difficulty level, subtitles, game hints and tutorials as we can see in Figure 1.

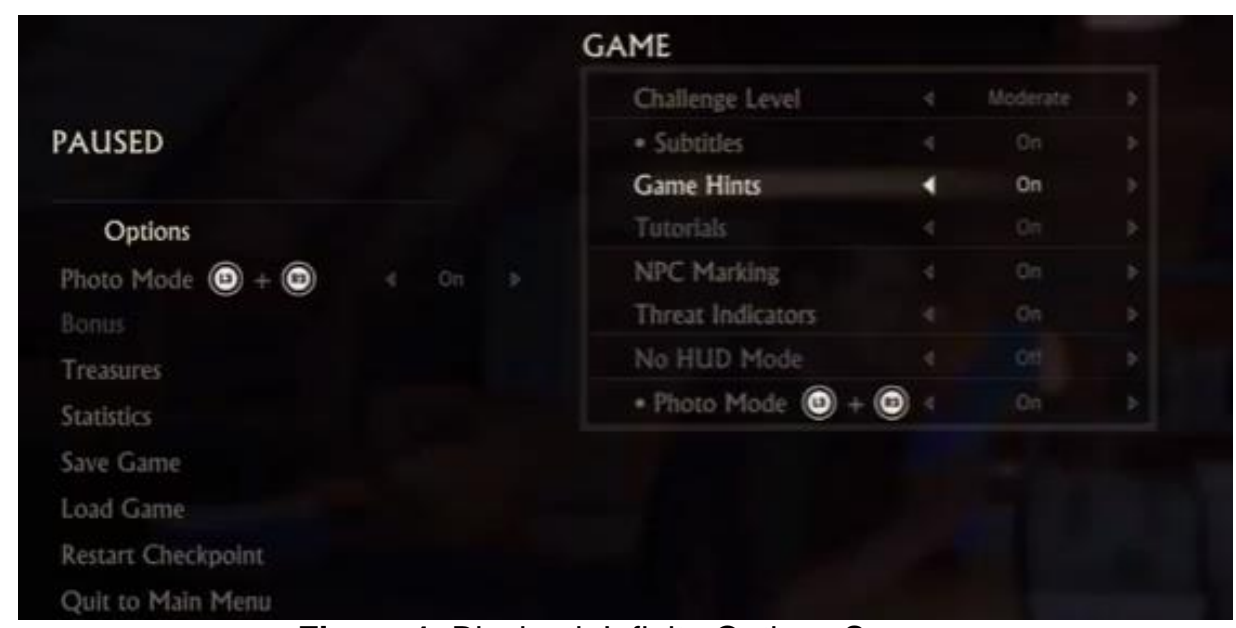

Figure 1. Bioshock Infinite Options Screen

On the other hand, Skulls of the Shogun is a strategy video game that allows to save the progress of the game at any time and restart it at the saved point. In Figure 2 we have all the related options.

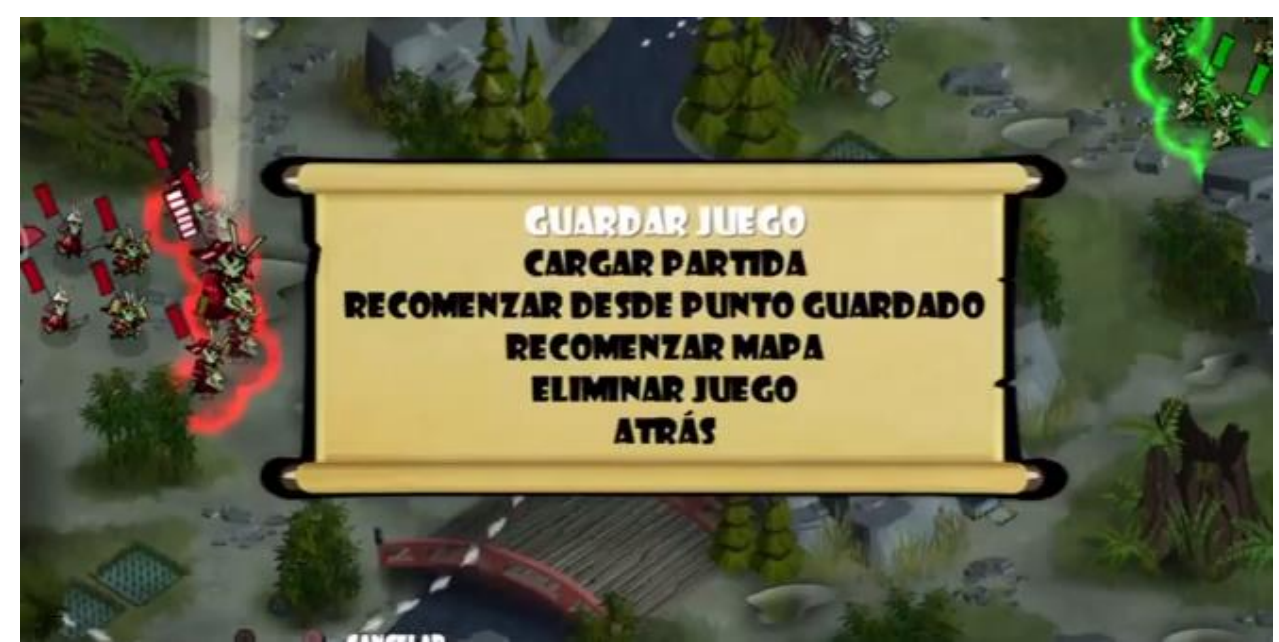

Figure 2. Skulls of the Shogun Save Options 
An interesting feature is present in the game Sproggiwood, which allows to configure up to six key options to execute a command as we can see in Figure 3. This feature is very important for people with learning disabilities or difficulty of pressing only one button at a time.

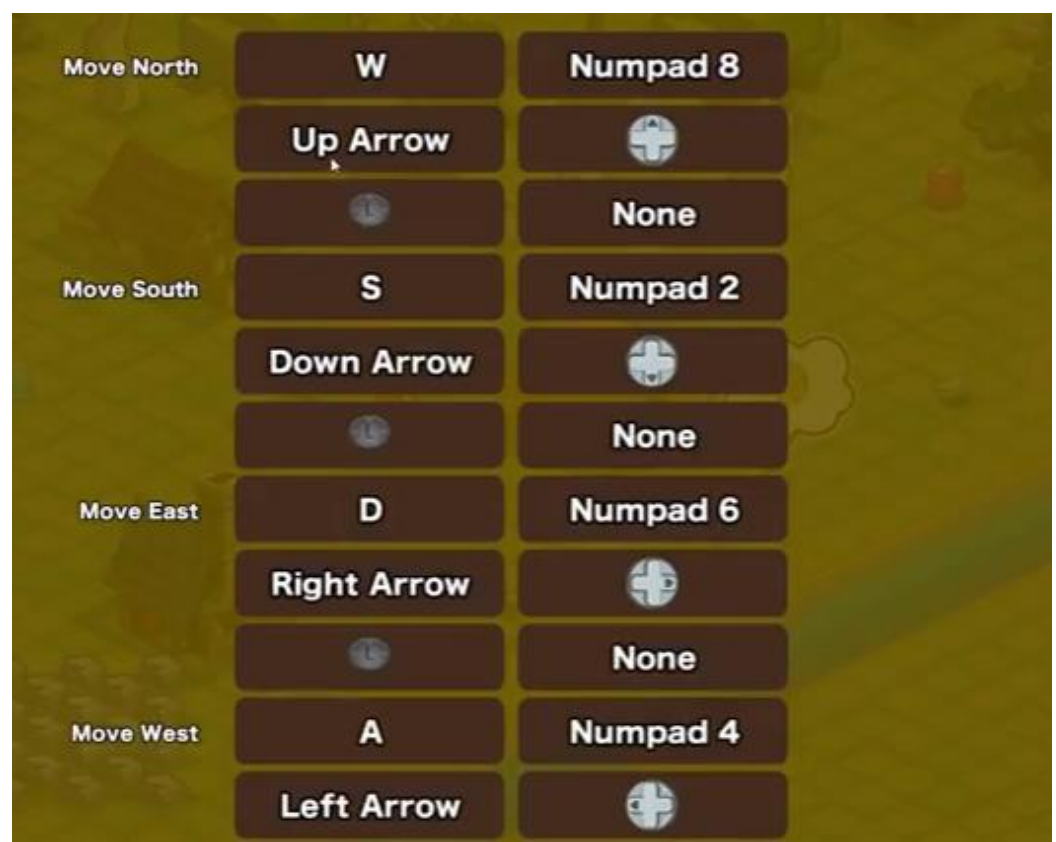

Figure 3. Sproggiwood Control Settings

\section{Guidelines Analysis Method}

Once an overview of the different guidelines has been given, it is necessary to analyze and group them into a new categorization. Duplicates will be deleted as part of the process.

The first step is to make a proposal of new categories. These categories will group the guidelines according to the complexity of applying them and the benefit they provide to people with cognitive disabilities. It is important to note that the perspective of complexity is from the point of view of the developer while the benefit is defined from the video game's end user view.

The categories proposed by several of the cited authors are analyzed. Also, the parameters and guidelines are revised and this leads to the definition of three new categories or levels. These new categories cover the full range of guidelines that have been considered:

- Low Level - Good: It refers to simple implementation complexity and good accessibility features.

- Medium Level - Better: It refers to a medium implementation complexity and better accessibility features.

- High Level - Best: It refers to a high implementation complexity and the best accessibility features.

Once the levels have been defined, each guideline is analyzed to assign them to the appropriate category. In this process, it is important to assess ease of implementation and the benefit for people with disabilities.

With the guidelines mapped in their respective category, we proceed to eliminate existing duplicates. It is important to note that the process of removing duplicates is done by carefully comparing the descriptions of each guideline. Every author handles their own descriptive language and a thorough review of each is necessary.

The result of both processes, the guidelines mapping in each category and the elimination of duplicates, are presented in Table 3. 
Table 3. Guidelines per Level

\begin{tabular}{|l|c|}
\hline \multicolumn{1}{|c|}{ Level } & Guidelines \\
\hline Low Level - Good & 13 \\
\hline Medium Level - Better & 15 \\
\hline High Level - Best & 16 \\
\hline
\end{tabular}

After this analysis, we proceed to verify those guidelines that can be used for the assessment of mobile video games. This process is carried out considering the characteristics and nature of the mobile devices, for example Android (Android Developers, n.d.) and iOS (Apple Developer, n.d.) accessibility features. The result is showed in Table 4.

Table 4. Mobile Devices Guidelines per Level

\begin{tabular}{|c|c|}
\hline Level & Guidelines \\
\hline \multirow{8}{*}{ Low Level - Good } & Use simple language \\
\hline & Customizable fonts (color, sizes) \\
\hline & Switch on/off graphic elements \\
\hline & Subtitles \\
\hline & In-game tutorials \\
\hline & Simple to difficult progression \\
\hline & Accessible menus \\
\hline & Sandbox modes \\
\hline \multirow{8}{*}{ Medium Level - Better } & Training levels \\
\hline & Objectives reminder during gameplay \\
\hline & Controls reminder during gameplay \\
\hline & Alternative sound files setup \\
\hline & Use explicit visual rewards \\
\hline & Possibility for repetition \\
\hline & Pause while text is being readed \\
\hline & Save settings \\
\hline \multirow{5}{*}{ High Level - Best } & Auto aim, ability to lock on a target \\
\hline & Speed settings \\
\hline & Self-voicing capability \\
\hline & Adjustable sensitivity/error tolerance \\
\hline & Auto-pass \\
\hline
\end{tabular}

Once the parameters are determined, an indicator is defined for each accessibility level. This indicator allows quantifying the accessibility of a serious game at each of the levels proposed. Each guideline should be analyzed in the video game and its compliance should be scored. The indicator for each level will be given by Equation 1:

$$
\sum_{i=1}^{i=n} x_{i}=x_{1}+x_{2}+\cdots+x_{n}
$$

Where $n$ refers to the number of guidelines that are available for each category and $x$ has the value of " 1 " or " 0 " taking into account if the game complies with it. For a general indicator of accessibility, we propose the summation of each level indicator as follows in Equation 2:

$$
\sum_{j=1}^{j=3} y_{j}=y_{1}+y_{2}+y_{3}
$$

In this case, $j$ corresponds to the number of levels proposed (1 - low, 2 - medium, 3 high) and $y$ is the value scored in each level by equation 1. As result, we will have a value that will allow us to have a general accessibility rating of the video game. 


\section{Serious Games Accessibility Assessment}

There are works that have proposed methodologies for the design of serious games. In (Rello, Bayarri, Otal, \& Pielot, 2014), for example, a method to improve the spelling of children with dyslexia is proposed. Also, in (Durango, Carrascosa, Gallud, \& Penichet, 2015) a serious game is presented to support children with special needs in their therapeutic experiences.

In the development of our work, we selected a mobile serious game from Google Play with the objective of evaluating its accessibility with the guidelines proposed in the previous section. The search string used was "serious games". The search result showed several entertainment applications of which we present and describe the first five in Table 5.

Table 5. Serious Games Search Result

\begin{tabular}{|c|c|c|}
\hline Game & Category & Icon \\
\hline Serious Games CEOE & Educational & \\
\hline DEAD TARGET: Zombie Shooting & Action & \\
\hline Help! The Serious Game & Simulation & \\
\hline $\mathrm{CIA}$ agente secreto escape historia 2 & Action & \\
\hline Multi Surgery Doctor Hospital & Role-game & \\
\hline
\end{tabular}

These results allow to open a line of research about video games cataloging in platforms like Google Play, considering that two games of the search do not belong to the category of "serious games". We will analyze the three that are related to the educational area.

The first mobile video game analyzed, Serious Games CEOE, is an app developed by the Confederación Española de Organizaciones Empresariales (CEOE). This mobile video game contains five serious games to promote healthy in the daily life and especially in the workplace (Confederación Española de Organizaciones Empresariales (CEOE), n.d.).

Each serious game has a different purpose:

- Stress Management: It is a game of awareness about the importance of stress management in the workplace.

- Healthy Life: This game is about of consciousness to the player about healthy eating habits.

- Move It: It is a game of awareness of healthy habits.

- The Office Room: This game allows the player to solve the riddles to end its workday of the healthiest fashion.

- Business Up: It is a real-time game whose goal is to grow a company through actions of health and safety at work.

The second game analyzed is Help! The Serious Game. This mobile video game is a 3D serious game designed and developed by the Human-Computer Interaction Lab at the University of Udine, Italy, in collaboration with the Regional Council of the Associations of 
Disabled Persons FVG. The game is aimed at improving the player's ability to help people with disabilities in emergency situations. There are scenarios such as earthquakes or fires, with the aim of helping a person with disabilities in the evacuation of a building. In the different levels of the game, people with physical, visual and auditory disabilities appears. The initial level, in each disability, is a training gym to learn the necessary concepts under the guidance of a firefighter ( $\mathrm{HCl}$ Lab University of Udine \& Regional Council of the Associations of Disabled Persons FVG, 2017).

The third game analyzed, Multi Surgery Doctor Hospital, is a mobile video game developed by Woofie Games. The objective of the game is to help, through surgeries, victims of a sandstorm that have caused an emergency situation in a city. There are four patients with different injuries that must be assisted, for which the player can perform open heart surgery, stomach surgery and ear surgery, abdominal surgery and even maternity surgery (Woofie Games, 2017).

These games were downloaded from Google Play and installed in a Samsung Galaxy S6 with Android 7.0 for their analysis, as we can see in Figure 4.

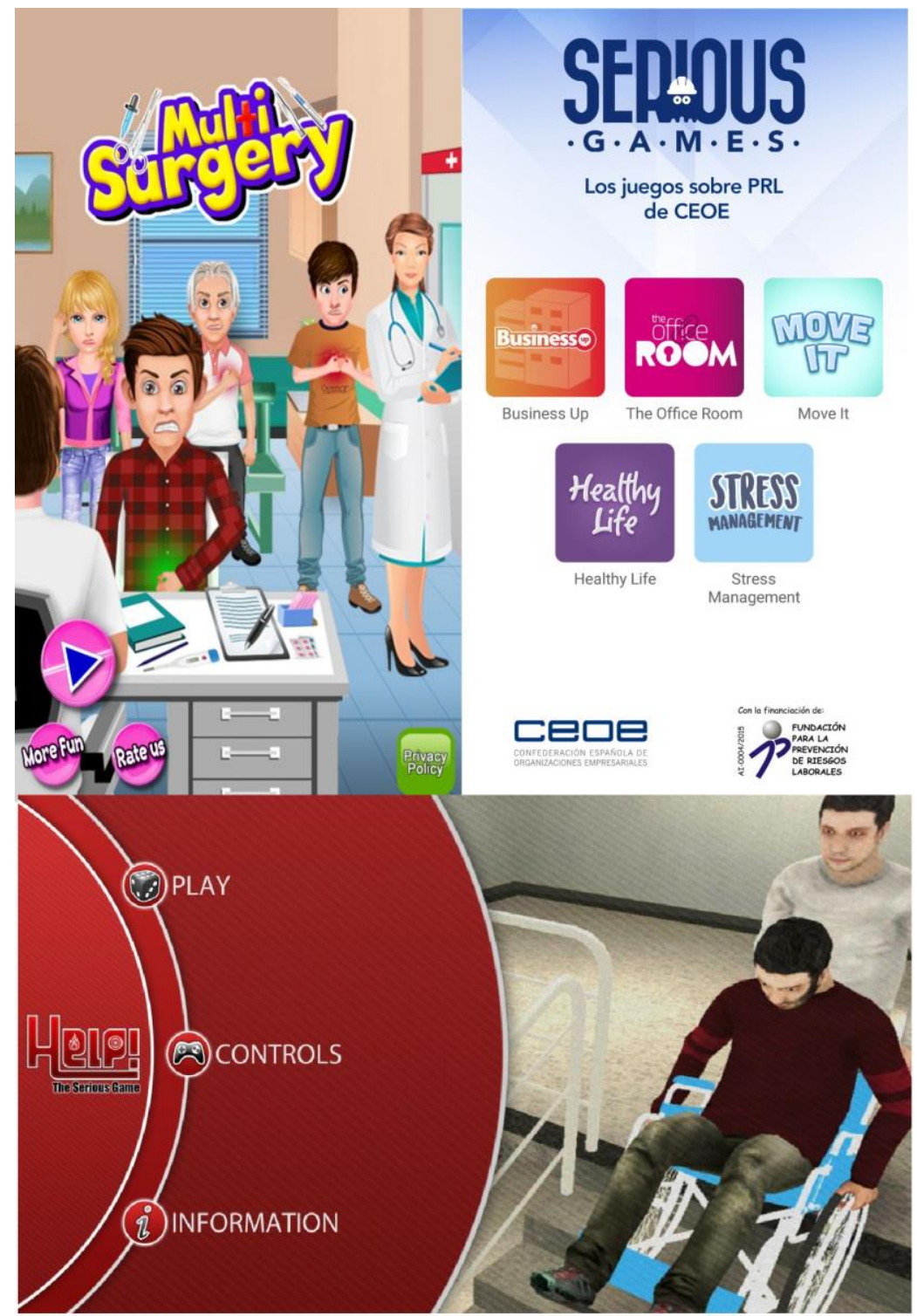

Figure 4. Serious Games (CEOE), Help! and Multi Surgery Initial Screen

Once the games were identified, the evaluation was carried out considering the guidelines in Table 4. Equation 1 was used to quantify the level of accessibility of each 
game. For this, each accessibility guideline was analyzed in each game and it was scored whether or not complies with it. To finalize the assessment, it was necessary to determine the total value of accessibility of the video games. Equation 2 was used and the result of all the process is presented in Figure 5.

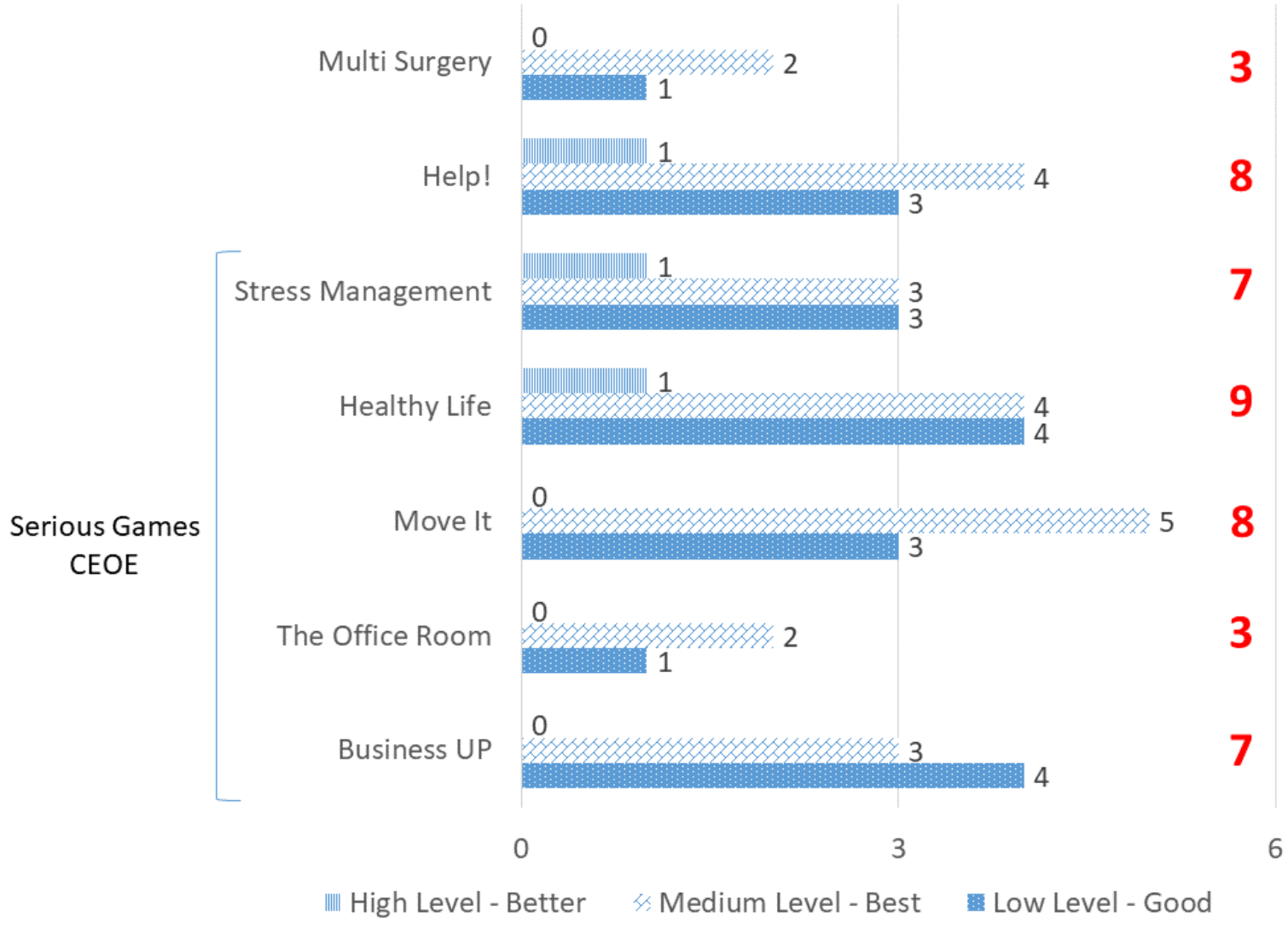

Figure 5. Accessibility Assessment Serious Games CEOE, Help! and Multi Surgery

In the figure, each bar shows the value of accessibility reached in each level and also, in the right of the bar with a big font size, we show the total value of accessibility reached by each video game. It is important to take into account that the maximum value of accessibility that can be reached is 21 , due to the number of guidelines that were determined, and the maximum score obtained was 9 for the Healthy Life game from Serious Games CEOE.

\section{Discussion of Results}

Each game complies with at least one of the accessibility guidelines collected for mobile devices. In the Low Level-Good, six of the seven games make use of a simple language that supports the development of the game. Also, four games have in-game tutorials and six have subtitles that allow to understand the different instructions of each game. At this same level, no game considers font customization, whether in size, color or type. Also none of them have accessible menus to provide a simplified interface that displays only the most commonly used controls in the menus.

In the Medium Level - Better, six of the seven games allow reminder of current objectives during game-play and only four allow the user to save settings. Also, all of them give the player the ability to repeat the game stages. On the other hand, in this level only one game offers controls reminder during game-play. Also, no game offers the opportunity 
to choose alternative sound files and only two have training levels. Finally, in this level, no game gives explicit visual rewards.

In the High Level - Best, the scenario is minimal because most of the games evaluated do not comply with the guidelines of this level. Only three games offer the ability to assist the player by offering the option for auto aim, or auto centering, the ability to lock on a target.

The total value of accessibility obtained for each video game is in the range of 3 to 9 , that is, between $14.2 \%$ and $42.8 \%$ on the maximum value of possible accessibility. The video games with the lowest value of accessibility are The Office Room and Multi Surgery and the highest is Healthy Life. These results allow us to understand that mobile video games in some cases lack accessibility features and in others they comply fairly.

To finalize this analysis, we should consider that the mobile serious games analyzed are only an example of assessment of the accessibility guidelines. It is important to note that the results vary from one game to another. With this analysis we want to emphasize the importance of considering this kind of guidelines in the mobile serious games development. On the other hand, this analysis only considers those guidelines that focus on the nature of mobile devices. The rest, which are also important, should be considered for video games in general.

\section{Conclusions and Future Work}

In this work, we seek to contribute to the community of people with disabilities, especially cognitive, due to the difficulty they may have in video games due to their condition. Taking into account the growth of serious games and their contribution to the teaching process, the accessibility parameters must be considered in their design and implementation. Non-accessible serious games are a limitation for people with disabilities and hinder equitable access to education. This is a right defined in the Article 24 of the United Nations Convention on the Rights of Persons with Disabilities (United Nations, 2017). Then, if education is a right for people with disabilities and the use of serious games in education is increasing, it is necessary to ensure that serious games are accessible.

On the other hand, the use of mobile devices has increased in recent years and this has motivated the development of more applications that may be available to more people. Video games are widely used by users of mobile devices and the serious games market can be very attractive for this segment. Taking this premise into account, many initiatives are defining good practices for the development of video games for people with disabilities. These initiatives should be considered by mobile video game developers because they contribute to the inclusion in the learning process through accessible mobile serious games.

This study allows us to give a first approach to a model of accessibility evaluation of video games. This also gives us the premise to propose in the future a method to develop serious games accessible on mobile devices, given the appropriate characteristics that meet the needs of people with cognitive disabilities. Once accessible serious games are available, accessibility tests can be conducted with people with disabilities. In these tests, the effectiveness of the accessibility characteristics of serious games can be evaluated. Researches and similar proposals can be made with other disabilities. The long-term goal is to propose a general framework of analysis and development of serious games accessible to any type of disability. That is why it is pertinent to continue analyzing other disabilities and developing serious accessible video games for a more general vision and to offer greater accessibility.

\section{Bibliography}

Accessible University. (2016). Defining Accessibility - Accessible University. Retrieved January 30, 2018, from http://www.accessibleuniversity.com/accessibilitybasics/defining-accessibility

Acosta, T., \& Luján-Mora, S. (2017). Análisis de la accesibilidad de los sitios web de las 
universidades ecuatorianas de excelencia. Enfoque UTE, 8(1), (pp. 46-61). https://doi.org/10.29019/enfoqueute.v8n1.133

Android Developers. (n.d.). Accessibility in Android. Retrieved January 30, 2018, from https://developer.android.com/guide/topics/ui/accessibility/index.html

Apple Developer. (n.d.). Accessibility on iOS. Retrieved January 30, 2018, from https://developer.apple.com/accessibility/ios/

CISCO. (2017). Cisco Visual Networking Index: Global Mobile Data Traffic Forecast Update, 2016-2021 White Paper - Cisco. Retrieved January 30, 2018, from http://www.cisco.com/c/en/us/solutions/collateral/service-provider/visual-networkingindex-vni/mobile-white-paper-c11-520862.html

Confederación Española de Organizaciones Empresariales (CEOE). (n.d.). Serious Games CEOE - Aplicaciones de Android en Google Play. Retrieved February 12, 2018, from https://play.google.com/store/apps/details?id=com.prevencontrol.seriousgamesceoe \&hl=es

Durango, I., Carrascosa, A., Gallud, J. A., \& Penichet, V. M. R. (2015). Using Serious Games to Improve Therapeutic Goals in Children with Special Needs. In Proceedings of the 17th International Conference on Human-Computer Interaction with Mobile Devices and Services Adjunct - MobileHCl'15 (pp. 743-749), New York, USA: ACM Press. https://doi.org/10.1145/2786567.2793696

Game accessibility guidelines. (n.d.). A straightforward reference for inclusive game design. Retrieved February 5, 2018, from http://gameaccessibilityguidelines.com/

GameLearn. (2015). The future of serious games through the lens of mobile devices. Retrieved February 12, 2018, from https://game-learn.com/the-future-of-seriousgames-through-the-lens-of-mobile-devices/

Ghannem, A. (2014). Characterization of Serious Games Guided by the Educational Objectives. In Proceedings of the Second International Conference on Technological Ecosystems for Enhancing Multiculturality, (pp. 227-233). https://doi.org/http://dx.doi.org/10.1145/2669711.2669904

Gikas, J., \& Grant, M. M. (2013). Mobile computing devices in higher education: Student perspectives on learning with cellphones, smartphones \& social media. The Internet and Higher Education, 19, (pp. 18-26). https://doi.org/10.1016/j.iheduc.2013.06.002

Guillén-Nieto, V., \& Aleson-Carbonell, M. (2012). Serious games and learning effectiveness: The case of It's a Deal! Computers \& Education, 58(1), (pp. 435-448). https://doi.org/10.1016/j.compedu.2011.07.015

Hatzigiannakoglou, P. (2015). Junk-Food Destroyer: Helping Adolescents with Down Syndrome to Understand Healthy Eating through Serious Game. In 7th International Conference on Games and Virtual Worlds for Serious Applications (VS-Games) (pp. 1-5). IEEE. https://doi.org/10.1109/VS-GAMES.2015.7295778

$\mathrm{HCl}$ Lab University of Udine, \& Regional Council of the Associations of Disabled Persons FVG. (2017). Help! The Serious Game - Aplicaciones de Android en Google Play. Retrieved February 11, 2018, from https://play.google.com/store/apps/details?id=it.uniud.hcilab.helpseriousgame

Holger, O., Tufiño, R., \& Estévez, J. (2017). Hacia la construcción de un dispositivo de asistencia para personas no videntes en el juego de cuarenta. Enfoque UTE, 8(4), (pp. 27-40). https://doi.org/10.29019/enfoqueute.v8n4.170

IGN. (2014). I'm a Disabled Gamer and This is My Story. Retrieved February 9, 2018, from http://www.ign.com/articles/2014/05/30/im-a-disabled-gamer-and-this-is-my-story

International Game Developers Association (IGDA) - Game, \& Accessibility SIG. (2004). Accessibility in Games: Motivations and Approaches. Retrieved February 5, 2018, from http://g3ict.org/download/p/fileld_776/productld_50

Jaramillo-Alcázar, A., \& Luján-Mora, S. (2017). Mobile Serious Games: An Accessibility Assessment for People with Visual Impairments. In Proceedings of the 5th International Conference on Technological Ecosystems for Enhancing Multiculturality (pp. 1-6). New York, USA: ACM Press. https://doi.org/10.1145/3144826.3145416 
Jaramillo-Alcázar, A., \& Luján-Mora, S. (2018). An Approach to Mobile Serious Games Accessibility Assessment for People with Hearing Impairments (pp. 552-562). Springer, Cham. https://doi.org/10.1007/978-3-319-73450-7_52

Jaramillo-Alcázar, A., Luján-Mora, S., \& Salvador-Ullauri, L. (2017a). A Mobile Serious Games Assessment Tool for People with Motor Impairments. In International Conference on Education Technology and Computers. (pp. 172-177). New York, USA: ACM Press. https://doi.org/10.1145/3175536.3175569

Jaramillo-Alcázar, A., Luján-Mora, S., \& Salvador-Ullauri, L. (2017b). Accessibility Assessment of Mobile Serious Games for People with Cognitive Impairments. In International Conference on Information Systems and Computer Science.

Koster, R. (2013). A theory of fun for game design.

Markets and Markets. (n.d.). Serious Game Market worth \$5,448.82 Million by 2020. Retrieved February 14, 2018, from http://www.marketsandmarkets.com/PressReleases/serious-game.asp

MediaLT. (2004). Guidelines for the development of entertaining software for people with multiple learning disabilities. Retrieved February 12, 2018, from http://www.medialt.no/rapport/entertainment_guidelines/index.htm

Michael, D., \& Chen, S. L. (2006). Serious games: games that educate, train and inform. Thomson Course Technology.

Rello, L., Bayarri, C., Otal, Y., \& Pielot, M. (2014). A computer-based method to improve the spelling of children with dyslexia. In Proceedings of the 16th international ACM SIGACCESS conference on Computers \& accessibility - ASSETS '14 (pp. 153-160). New York, USA: ACM Press. https://doi.org/10.1145/2661334.2661373

Sauve, L., Senecal, S., Kaufman, D., Renaud, L., \& Leclerc, J. (2011). The Design of Generic Serious Game Shell. In International Conference on Information Technology Based Higher Education and Training (pp. 1-5). IEEE. https://doi.org/10.1109/ITHET.2011.6018675

Superdata. (2016). SuperData Research | Games data and market research " Worldwide digital games market. Retrieved February 12, 2018, from https://www.superdataresearch.com/market-data/market-brief-year-in-review/

The AbleGamers Foundation. (2012). A Practical Guide to Game Accessibility. Retrieved February 12, 2018, from http://includification.com/AbleGamers_Includification.pdf

The Radicati Group. (2014). Mobile Statistics Report, 2014-2018. Retrieved February 12, 2018, from http://www.radicati.com

Tore, P. A. Di, Tore, S. Di, Ludovico, L. A., \& Mangione, G. R. (2014). MADRIGALE: A Multimedia Application for Dyslexia and Reading Improvement GAmifying Learning Experience. In International Conference on Intelligent Networking and Collaborative Systems (pp. 486-491). IEEE. https://doi.org/10.1109/INCoS.2014.48

United Nations. (2017). Convention on the Rights of Persons with Disabilities (CRPD). Retrieved January 19, 2018, from https://www.un.org/development/desa/disabilities/convention-on-the-rights-ofpersons-with-disabilities.html

US Census Bureau Public Information Office. (2012). Nearly 1 in 5 People Have a Disability in the U.S., Census Bureau Reports - Miscellaneous - Newsroom - U.S. Census Bureau. Retrieved February 12, 2018, from https://www.census.gov/newsroom/releases/archives/miscellaneous/cb12-134.html

Uzuegbunam, N., Wing-Hang Wong, Cheung, S. S., \& Ruble, L. (2015). MEBook: Kinectbased self-modeling intervention for children with autism. In IEEE International Conference on Multimedia and Expo (ICME) (pp. 1-6). IEEE. https://doi.org/10.1109/ICME.2015.7177518

WebAIM. (2013). Cognitive Disabilities. Retrieved February 14, 2018, from http://webaim.org/articles/cognitive/

Woofie Games. (2017). Multi Surgery Doctor Hospital - Aplicaciones de Android en Google Play. Retrieved February 11, 2018, from 
https://play.google.com/store/apps/details?id=com.woofie.multi.surgery

World Health Organization. (2001). International Classification of Functioning, Disability and Health (ICF).

World Health Organization. (2011). World Report on Disability. Retrieved February 11, 2018, from http://www.who.int/disabilities/world_report/2011/report.pdf 